\title{
ARTIGO
}

\section{Dos fatores individuais aos sociais: paradigmas em Segurança e Saúde no Trabalho em campanhas preventivas audiovisuais no Brasil}

\author{
From individual to social factors: paradigms in Occupational Safety and \\ Health in preventive audiovisual campaigns in Brazil
}

\section{Leo Vinicius Maia Liberato'}

RESUMO: Apreender qual paradigma ou modelo de concepção de riscos e de prevenção em Segurança e Saúde no Trabalho prevalece em campanhas preventivas no Brasil e, principalmente, se há diferença de prevalência de acordo com os atores sociais que produzem as campanhas, é o objetivo da pesquisa apresentada neste artigo. Para tanto, construímos dois tipos-ideias de concepção de riscos e de prevenção a partir da história e da literatura de SST e realizamos uma análise de conteúdo num corpus formado por setenta vídeos de campanhas preventivas, produzidos por sindicatos de trabalhadores, entidades estatais e entidades patronais. Entre outras associações que encontramos, verificou-se que nas campanhas de sindicatos dos trabalhadores prevalece uma abordagem com ênfase em fatores sociais e de organização do trabalho, enquanto nas campanhas das entidades empresariais prevalece a abordagem com ênfase em comportamentos individuais.

Palavras-chave: prevenção em SST; comunicação; modelos de prevenção; ideologia; cultura de segurança.

ABSTRACT: Understanding which paradigm or model of risk conception and prevention in Occupational Safety and Health is prevailing in preventive campaigns in Brazil and, especially, if there is a difference in prevalence according to the social actors that produce the campaigns, is the objective of the research. presented in this article. To this end, we built two Ideal types of risk conception and prevention from the history and literature of OSH and conducted a content analysis in a corpus of seventy preventive

1 Tecnologista da Fundacentro - Fundação Jorge Duprat e Figueiredo. Doutor em Sociologia Política pela Universidade Federal de Santa Catarina (UFSC). 
Dos fatores individuais aos sociais: paradigmas em Segurança e Saúde no Trabalho em campanhas preventivas audiovisuais no Brasil

campaign videos produced by workers' unions, state entities and employers. Among other associations we found, it was found that in workers' union campaigns, an approach with emphasis on social and work organization factors prevails, while in corporate entity campaigns, the approach with emphasis on individual behaviors prevails.

Keywords: OSH prevention; communication; prevention models; ideology; safety culture.

\section{INTRODUÇÃO}

Quais paradigmas de prevenção prevalecem em campanhas preventivas de Segurança e Saúde no Trabalho, produzidas no Brasil? Este artigo busca contribuir para responder a essa questão.

Mais especificamente, buscamos apreender quais conteúdos de mensagens preventivas estão sendo produzidos na sociedade, através de órgãos estatais, entidades empresariais e dos trabalhadores; que cultura ou paradigma de prevenção em SST elas expressam e reproduzem. Estaria o paradigma correspondente à concepção de "ato inseguro" focado na explicação de acidentes pelo comportamento individual dos operadores, prevalecendo ainda em campanhas preventivas? Haveria diferença de paradigma ou abordagem nas campanhas produzidas por diferentes atores: Estado, sindicatos de trabalhadores e entidades patronais?

Para responder a essas perguntas, partimos do reconhecimento de que existem diferentes modelos de prevenção, pois há diferentes concepções e interpretações de riscos, responsáveis pela prevenção e pelos valores e prioridades que as determinam (MENÉNDEZ-NAVARRO, 2019). Nesse sentido, se falamos em paradigmas de prevenção é porque concebemos, mesmo que em linhas gerais, aspectos e características que os conformam e os identificam. Construímos, assim, dois tiposideais de paradigmas ou abordagens de prevenção em SST que nos serviram de referenciais analíticos.

Como método de pesquisa utilizou-se a análise de conteúdo de um corpus de vídeos de campanhas preventivas de SST (AARTS; BAUER, 2008). A construção desse corpus foi realizada através de uma seleção de vídeos de campanhas preventivas disponibilizados publicamente na web, produzidos no período dos doze anos anteriores à seleção, isto é, de 2006 a julho de 2018. De modo a englobar os atores com interesse direto em SST, o corpus foi construído com vídeos de campanhas 
produzidas por entidades estatais (33 vídeos), entidades empresariais (26 vídeos) e entidades dos trabalhadores (11 vídeos), totalizando 70 vídeos.

\section{HISTORICIZANDO AS ABORDAGENS DE SST}

Na história da Saúde e Segurança no Trabalho, podemos distinguir duas linhas gerais de abordagem que, embora evoluindo em suas formas e conceitos, têm-se perpetuado ao longo do tempo. Uma focada no indivíduo, comportamental, outra focada no ambiente ou nas condições, sejam elas econômicas, de produção, sociais etc.

Enquanto a saúde no trabalho ganha dimensão no século XIX, a segurança ganha importância somente no século $\mathrm{XX}$, num período de rápido crescimento do taylorismo e da mecanização dos processos de produção. Na sua pesquisa sobre a história da SST, nos Estados Unidos, Reino Unido e Holanda, Gulijk, Swuste e Zwaard (2010) apontaram que duas abordagens relativas a acidentes se desenvolveram nas primeiras décadas do século XX: uma abordagem ambiental, focada nos condicionantes do ambiente físico e das condições de trabalho e produção; e outra, conhecida principalmente como propensão ao acidente (accident proness), que explicava o acidente por uma suscetibilidade individual de determinados trabalhadores a se acidentarem. Suscetibilidade essa, baseada em estudos psicológicos.

Essa concepção, que individualizava ao trabalhador a causa e a responsabilidade pelo acidente, prevaleceu também no Brasil. Como mostra Faleiros (1992), em relação à década de 1950, os patrões adotavam "a prática do controle profissional da aptidão e inaptidão dos trabalhadores em vez da prática do controle das condições de trabalho" (FALEIROS, 1992, p.142). Em análise documental do período, ela aponta que: "para realizar essa tarefa de adaptação [dos trabalhadores a suas funções], as empresas exigem, sobretudo, o exame de seleção, para 'detectar o fator humano predisposto ao acidente" (FALEIROS, 1992, p. 231). O personagem "Zé Desastre", criado pela GM do Brasil, no final da década de 1940, um "sujeito relapso e debochado", é ilustrativo de como essa concepção se expressou na produção de mensagens pelas empresas (NEGRO, 2004, p. 214). A teoria da propensão ao acidente esteve bastante presente no Brasil, pelo menos até a década de 1970. Como salientam Gulijk, Swuste e Zwaard (2010), essa teoria psicológica foi a base científica para a ideia de ato inseguro, e embora o conceito de propensão ao acidente esteja superado, concepções comuns a ele, como o foco no comportamento dos trabalhadores e a monocausalidade, continuam a influenciar programas e abordagens de segurança no trabalho. O treinamento e principalmente a ênfase em obediência a normas e procedimentos aparecem, então, como meio de determinar e controlar atos e 
Dos fatores individuais aos sociais: paradigmas em Segurança e Saúde no Trabalho em campanhas preventivas audiovisuais no Brasil

comportamentos dos trabalhadores, de modo a prevenir acidentes. A suscetibilidade e a responsabilização individuais têm sido também uma forma de explicar e lidar com doenças ocupacionais (DAVIES, 2016).

Distintamente dessa abordagem, individualizante, também surgiu uma abordagem com foco nos condicionantes ambientais ou sociais (NAVARRO, 1980; NICHOLS, 1999). O próprio erro e comportamento humanos, relacionados a acidentes de trabalho, passaram a ser compreendidos como consequência de fatores sistêmicos (RASMUSSEN, 1997; REASON, 1990). Fortalecendo uma perspectiva ambiental, social ou sistêmica de prevenção em SST, já é amplamente reconhecido que uma série de fatores de risco psicossociais do trabalho, relacionados a decisões políticas e gerenciais, amplia a morbidade e mortalidade, como por exemplo: baixa justiça organizacional; altas demandas de trabalho; insegurança de emprego; exposição a trabalho em turno; baixo controle do trabalho; baixo apoio social no trabalho; longa jornada de trabalho/horas extras (PFEFFER, 2018). Por sua vez, a forma de remuneração, como o pagamento por peça ou produção, é solidamente reconhecida como fator organizacional de acidentes e doenças.

Desse modo, se a individualização se direciona a mudanças comportamentais dos indivíduos, por sua vez, o foco em fatores ambientais ou sociais, como as decisões gerenciais que colocam os trabalhadores e, por vezes, também comunidades em risco, pode levar a ações coletivas para mudar as fontes estruturais desse risco (ZOLLER, 2009). Ora, essas fontes estruturais do risco se vinculam a relações econômicas e sociais, o que implica, em geral, atores com interesse em mantê-las. Por isso, as abordagens explicativas e preventivas em SST não estão isentas de funções ideológicas (HALL, 1996; NAVARRO, 1980).

Alexander (1988) define ideologia como um conjunto de pressupostos incorporados num conhecimento sobre o mundo. Pressupostos esses que constituiriam esse conhecimento apesar de não serem imediatamente evidentes. A ideologia, assim, segundo ele, seria algo distinto do conhecimento, e diria respeito à ocultação de certas relações de classe e poder. Betoni (2015) desenha uma definição semelhante quando afirma que "as ideologias hegemônicas são articuladas estrategicamente para ocultar, não a realidade em si, mas sim a permanência insistente dos antagonismos de classe" (BETONI, 2015, p. 66). A ideologia dominante, para além de um conjunto de ideias, crenças e valores de um grupo, ou para além de um conjunto de pressupostos incorporados num conhecimento sobre o mundo - atributos comuns às ideologias -, teria, portanto, a função de ocultar os antagonismos de classe, as relações de poder.

Laborare. Ano III, Número 4, Jan-Jun/2020, pp. 15-31. ISSN 2595-847X. https://trabalhodigno.org/laborare DOI: https://doi.org/10.33637/2595-847x.2020-43 
Davies (2016), por exemplo, mostra como os programas de terapias laborais por ele estudados operam ideologicamente, ao individualizarem a desafecção do trabalhador ou ao reduzi-la a questões de micro-arranjos do local de trabalho, desviando, assim, da crítica às estruturas socioeconômicas que determinam a organização do trabalho. Alexander (1988), por sua vez, vê a construção da etiologia da doença a partir do risco individual, como uma construção ideológica. Allender, Colquhoun e Kelly (2006), estudando o programa de saúde laboral, numa empresa transnacional de tecnologia da informação, apontam que o discurso desse programa levava ao alinhamento dos objetivos pessoais dos trabalhadores aos objetivos da empresa - o que nos remete ao papel da ideologia dominante de ocultar os antagonismos de classe. Esse alinhamento se dava através do discurso que encorajava os empregados a se responsabilizarem por sua saúde e a mudarem seu comportamento para serem saudáveis. Por isso, numa análise de discurso ou de conteúdo de mensagens, cabe também investigar como os atores sociais concorrem para moldar a realidade social de acordo com seus interesses (NELKIN, 1985).

O papel dos discursos especialistas em SST já foi abordado por diferentes estudos, como Nelkin (1985) e Walters (1985), os quais sugerem que eles funcionam, sobretudo obscurecendo e desviando-se dos riscos ambientais. Mas, dentro do campo especialista de SST, é preciso salientar uma espécie de separação que há entre a evolução do que podemos chamar de campo científico ou acadêmico de SST, e a evolução do campo dos profissionais de SST. Como apontam Gulijk, Swuste e Zwaard (2010), esse dois campos parecem fazer parte de dois mundos separados, com os conhecimentos e a evolução do campo de pesquisa e ciência em SST não necessariamente penetrando - ou não como se poderia esperar - no campo de atuação dos profissionais de SST. Filgueiras (2017), nesse mesmo sentido, ressalta esse fosso: a abordagem hegemônica em SST, a abordagem individualizante, estaria em desacordo com a produção técnica e acadêmica desenvolvida nas últimas décadas.

Em termos de Gestão de SST, as abordagens individual e ambiental possuem diferentes repercussões. Como revela Filgueiras (2017), a abordagem individualizante seria menos eficiente que a abordagem focada no ambiente do trabalho por três razões: 1) a abordagem sobre o ambiente diminui as probabilidades de agravos, pois implica em número muitíssimo menor de decisões para que um agravo não ocorra; 2) ao contrário da abordagem no ambiente de trabalho, na abordagem individualizante as humanas e naturais "falhas" cognitivas podem levar a um acidente; 3) o controle da gestão (determinação de ritmos, metas, jornadas etc.) não é fundamentalmente exercido pelos indivíduos trabalhadores. 
Dos fatores individuais aos sociais: paradigmas em Segurança e Saúde no Trabalho em campanhas preventivas audiovisuais no Brasil

Essas abordagens também implicam diferentes dispositivos de Gestão em SST. Uma vez que a abordagem individualizante ou comportamental tende a se fixar no cumprimento de normas e procedimentos, a Gestão de SST tende a se basear em dispositivos de fiscalização e punição, fomentando, assim, que situações que geram não conformidades sejam escondidas da hierarquia que, por sua vez, se tornam alheias à realidade do trabalho. Já a abordagem com foco ambiental e organizacional, visando entender as decisões e ações dos indivíduos, como resultado da organização do trabalho e do ambiente social em que se encontram, tende a necessitar de dispositivos de compartilhamento de experiência, de diálogo, valorizando o saber do trabalhador.

\section{A CARACTERIZAÇÃO DOS TIPOS-IDEAIS PARA ANÁLISE}

Existem diferentes modelos de conceber e prevenir os riscos ocupacionais (MENÉNDEZ-NAVARRO, 2019). E, vimos resumidamente, em linhas gerais, que é possível distinguir duas concepções constituídas ao longo da história. Para melhor enxergarmos esses modelos ou paradigmas que coexistem nas mensagens preventivas produzidas pelos atores sociais, precisamos caracterizá-los minimamente. Com essas caracterizações nos aproximamos da construção de tipos-ideais (WEBER, 1999), que nos serviram para realizar uma análise comparativa do conteúdo de campanhas preventivas em SST.

$\mathrm{Na}$ Tabela 1, sintetizamos características da abordagem preventiva relativa ao paradigma dominante, correspondente à corrente histórica comportamental focada no indivíduo. Para essa caracterização, nos baseamos mais diretamente em Almeida (2006) e Menéndez-Navarro (2019).

Tabela 1 - Caracterização do paradigma dominante ou cultura hegemônica de prevenção em SST.

\begin{tabular}{|c|l|}
\hline \multicolumn{2}{|c|}{ Paradigma dominante } \\
\hline i) & $\begin{array}{l}\text { centrada na explicação de acidentes por erros e falhas humanas que, por } \\
\text { sua vez, costumam ser explicados por fatores individuais como } \\
\text { "negligência", "descuido", "imprudência", "falta de atenção", } \\
\text { "inexperiência" etc.; }\end{array}$ \\
\hline ii) & $\begin{array}{l}\text { normalmente esses fatores são atribuídos aos trabalhadores diretamente } \\
\text { ligados à operação em que ocorre o acidente ou agravo; }\end{array}$ \\
\hline iii) & $\begin{array}{l}\text { ela tende a focar no comportamento do trabalhador e na obediência às } \\
\text { normas, dirigindo-se, portanto, ao trabalhador; }\end{array}$ \\
\hline
\end{tabular}




\begin{tabular}{|c|l|}
\hline iv) & $\begin{array}{l}\text { conceitos de "ato inseguro" e "condição insegura" são frequentes na } \\
\text { explicação ou determinação de causa de acidentes; }\end{array}$ \\
\hline v) & $\begin{array}{l}\text { a obediência às regras e procedimentos é conquistada através de vigilância, } \\
\text { e a disciplina imposta por um sistema de recompensas e punições; }\end{array}$ \\
\hline vi) & campanhas de prevenção com apelo ao medo; \\
\hline vii) & $\begin{array}{l}\text { foco no uso de EPI (Equipamento de Proteção Individual), na gestão de } \\
\text { estresse, resiliência humana e em seleção e treinamento, em relação a } \\
\text { outras medidas de proteção ou de prevenção (eliminação da fonte de risco, } \\
\text { proteções coletivas, mudanças de processo e de organização do trabalho } \\
\text { etc.). }\end{array}$ \\
\hline
\end{tabular}

Elaboração do autor a partir de Almeida (2006) e Menéndez-Navarro (2019).

Importante salientar que esse tipo-ideal que denominamos de paradigma dominante se vincula, assim, à responsabilização da própria vítima ou de colegas na operação. De modo geral, as explicações e abordagens individualizantes tendem a levar os trabalhadores a aceitarem os riscos e os esconderem, se somando a outros fatores de aceitação de riscos como a instabilidade do emprego, a normalização dos perigos e a cultura de virilidade presente principalmente entre trabalhadores do sexo masculino (HALL, 1996; ZOLLER, 2009). O paradigma dominante está centrado naquilo que Filgueiras (2017) também descreveu como individualização da saúde e segurança do trabalho. A individualização seria de tal forma assimilada na sociedade que formaria o senso comum, sendo passivamente aceita ou mesmo ativamente reproduzida pelos próprios trabalhadores e pelos órgãos estatais (FILGUEIRAS, 2017).

Por sua vez, uma abordagem que procuraria superar as limitações do paradigma dominante levaria em conta, também, a partir de Almeida (2016) e MenéndezNavarro (2019), os elementos expostos na Tabela 2. Nomeamos esse tipo-ideal de abordagem sistêmica.

\section{Tabela 2 - Caracterização da abordagem sistêmica de prevenção em SST.}

\begin{tabular}{|c|l|}
\hline \multicolumn{2}{|c|}{ Abordagem sistêmica } \\
\hline a) & $\begin{array}{l}\text { fatores organizacionais e sociais, constituindo o que se poderia chamar de } \\
\text { abordagem sistêmica; }\end{array}$ \\
\hline b) & $\begin{array}{l}\text { a diversidade de atores responsáveis e distantes da operação onde ocorre o } \\
\text { agravo ou acidente; }\end{array}$ \\
\hline c) & $\begin{array}{l}\text { a multicausalidade do agravo ou acidente de trabalho (causas imediatas, } \\
\text { subjacentes e distantes da operação), ou até mesmo uma perspectiva para } \\
\text { além da concepção determinística de causa. }\end{array}$ \\
\hline
\end{tabular}

Elaboração do autor a partir de Almeida (2006) e Menéndez-Navarro (2019).

Laborare. Ano III, Número 4, Jan-Jun/2020, pp. 15-31. ISSN 2595-847X. https://trabalhodigno.org/laborare DOI: https://doi.org/10.33637/2595-847x.2020-43 
Dos fatores individuais aos sociais: paradigmas em Segurança e Saúde no Trabalho em campanhas preventivas audiovisuais no Brasil

Como abordagem alternativa à dominante, ela é mais incipiente e com menos elementos identificáveis pelas práticas, de modo a caracterizá-la ou construí-la como tipo-ideal.

\section{PROCEDIMENTOS DA CONSTRUÇÃO DO CORPUS DE VÍDEOS}

Após uma investigação exploratória, buscando vídeos online de campanhas preventivas em SST, decidimos por vídeos disponibilizados publicamente numa mesma plataforma para compor o corpus, o YouTube. A escolha se deu por se tratar de uma plataforma de amplo conhecimento e acesso público, e porque os vídeos de campanhas preventivas de SST, nele disponibilizados, eram mais do que suficientes para a construção do corpus.

Para entidades do Estado, incluímos vídeos de campanhas produzidos e disponibilizados no YouTube pelo Ministério do Trabalho, Ministério Público do Trabalho e Tribunal Superior do Trabalho. Por parte do empresariado, selecionamos vídeos de campanhas do chamado Sistema $\mathrm{S}$, embora não tenhamos encontrado campanhas preventivas através de vídeos de todas as entidades desse sistema. Buscamos vídeos das seguintes entidades: Serviço Social da Indústria (Sesi), Serviço Social do Comércio (Sesc) e Fecomércio/CNC/Senac; Serviço Nacional de Aprendizagem Rural (Senar) e CNA; Serviço Brasileiro de Apoio às Micro e Pequenas Empresas (Sebrae); e Serviço Social do Transporte (Sest) e CNT/Senat. No levantamento para a construção do corpus, nos deparamos com vídeos da Câmara Brasileira da Indústria da Construção, que também selecionamos como representativos das entidades patronais. Do mesmo modo, selecionamos também alguns vídeos da Vale, segunda maior empresa do país ${ }^{2}$, pois possuía vídeos bem produzidos de campanhas preventivas.

O período de coleta foi o mês de julho de 2018, compreendendo vídeos que fossem produzidos/disponibilizados entre 2006 e a data da coleta. Esse período foi escolhido por ser amplo o suficiente para permitir uma satisfatória variedade de vídeos para a construção do corpus sem que, no entanto, comprometesse um retrato atual das campanhas. As palavras ou expressões utilizadas para a busca e seleção dos vídeos na plataforma YouTube foram: "prevenção", "acidente", "doença", "saúde", "assédio moral", "riscos psicossociais", "condições de trabalho" e "ambiente de trabalho". Posteriormente, verificamos se os vídeos tratavam de assunto referente à prevenção em SST, excluindo os que fossem reportagens de eventos sobre o tema. O que nos interessava era a abordagem preventiva, e não, por exemplo, as abordagens

2 Não encontramos vídeos públicos online de prevenção em SST de outras grandes empresas brasileiras.

Laborare. Ano III, Número 4, Jan-Jun/2020, pp. 15-31. ISSN 2595-847X. https://trabalhodigno.org/laborare DOl: https://doi.org/10.33637/2595-847x.2020-43 
reparatórias e de reinserção no trabalho. Outros vídeos que apareceram em outras buscas ou que vieram a nosso conhecimento ao acaso também foram levados em consideração para a formação do corpus.

É preciso ressaltar que a busca realizada com as palavras ou expressões mencionadas acima tendem a levar a vídeos com concepções preventivas próprias de um campo bem delimitado e estabelecido de SST. Abordagens que não separam o processo produtivo, a organização do trabalho e a saúde são mais difíceis de serem detectadas por uma busca com esses termos. Esse é um entre outros prováveis motivos para as entidades dos trabalhadores aparecerem com número menor de vídeos de campanhas de SST na nossa busca. Desse modo, se pensarmos no movimento operário italiano nos anos 1970, a prevenção em SST não era algo separado e nem tão visível como um tema em si. Ela era em grande parte inseparável da luta contínua pelo controle do processo produtivo (LIBERATO, 2014). O fato é que as centrais sindicais parecem não produzir vídeos com temática relacionada a condições de trabalho e saúde do trabalhador. A produção dos vídeos de campanhas sobre esses temas que encontramos e que selecionamos para o corpus está dispersa entre os inúmeros sindicatos locais e por categorias, que caracterizam o nosso sindicalismo oficial.

Cabe destacar também que foram preteridos vídeos de campanhas preventivas cujo conteúdo focava em estatística de acidentes e adoecimentos ou na descrição da atividade de algum órgão estatal. Também não foram selecionados vídeos de programas de instrução de procedimentos e vídeo-aulas de SST.

Compuseram o corpus 33 vídeos de entidades estatais, 11 vídeos de entidades sindicais dos trabalhadores e 26 vídeos de entidades patronais, totalizando 70 vídeos.

\section{PROCEDIMENTOS DA ANÁLISE DE CONTEÚDO}

Nossa preocupação na pesquisa não foi confirmar uma hipótese, que seria um truísmo, de que o paradigma dominante prevalece nos vídeos de campanhas preventivas de SST. Mas, sim, perceber se há diferença e quais as diferenças do conteúdo das mensagens de acordo com quem produz e sobre o que se produz, tendo como referência os tipos-ideais que construímos.

Para a análise de conteúdo de vídeos, a principal referência metodológica que usamos foi Rose (2008). Contudo, a análise de conteúdo realizada não visava identificar representações de algo ou de alguém, mas, sim, identificar elementos que caracterizam um tipo-ideal. Portanto, nossa tarefa foi a de identificar no conteúdo dos 
Dos fatores individuais aos sociais: paradigmas em Segurança e Saúde no Trabalho em campanhas preventivas audiovisuais no Brasil

vídeos os traços e características que compõem os tipos-ideais de paradigmas de SST que formulamos.

Os objetos de interpretação nos vídeos foram: forma narrativa; contexto; ambiente; linguagem não verbal; linguagem verbal. Identificamos a partir desses objetos de interpretação, com a frequência em que aparecem: os riscos, perigos e consequências abordados; os elementos de "i" a "vii", listados na Tabela 1, que utilizamos para caracterizar o paradigma dominante de prevenção em SST; os elementos "a", "b" e "c", listados na Tabela 2, que utilizamos para caracterizar a abordagem sistêmica de prevenção em SST.

Evidentemente, a identificação dos elementos descritos acima possui um grau relativamente elevado de subjetividade, principalmente a identificação dos elementos que caracterizam os tipos-ideais construídos. Mas, para que o resultado fosse o mais independente possível do analista/pesquisador, estabelecemos alguns critérios na análise. Consideramos que um vídeo reproduzia os conceitos de "ato inseguro" e "condição insegura" apenas se esses conceitos fossem nomeados no vídeo. Como os vídeos eram compostos em vários casos por diferentes contextos, situações e histórias, a contagem de frequência marcou o número de contextos, situações ou histórias que determinado elemento esteve presente. Por isso, a frequência de um elemento não corresponde necessariamente ao número de vídeos em que ele aparece.

\section{RESULTADOS E DISCUSSÃO}

$\mathrm{Na}$ análise de conteúdo do corpus, pudemos observar, quanto aos paradigmas de prevenção (Tabela 3), que enquanto no conjunto de vídeos das entidades estatais há uma distribuição relativamente proporcional de frequências dos elementos que caracterizam o paradigma dominante e a abordagem sistêmica, no conjunto dos vídeos das entidades sindicais, é bastante forte a prevalência de elementos da abordagem sistêmica, e no conjunto de vídeos das entidades patronais, de modo inverso, é bastante nítida a prevalência de elementos do paradigma dominante.

As expressões "ato inseguro" ou "condição insegura" apareceram apenas quatro vezes no corpus, sendo três delas via entidades patronais. No entanto, pela alta frequência do elemento 'iii' do tipo-ideal paradigma dominante, podemos perceber que são conceitos ainda bastante vigentes embora não sejam muito nomeados nos vídeos de campanhas preventivas contemporâneos. 
Tabela 3 - Frequências dos elementos do "paradigma dominante" e da "abordagem sistêmica" nas mensagens dos vídeos.

\begin{tabular}{|c|c|c|c|c|c|c|c|c|c|c|}
\hline Vídeos & \multicolumn{7}{|c|}{ Paradigma dominante } & \multicolumn{3}{|c|}{ Abordagem sistêmica } \\
\hline & i & ii & iii & iv & v & vi & vii & a & b & c \\
\hline Estatais & 8 & 7 & 14 & 1 & 8 & 5 & 13 & 11 & 15 & 4 \\
\hline Sindicais & 0 & 0 & 0 & 0 & 1 & 0 & 0 & 16 & 2 & 6 \\
\hline Patronais & 19 & 20 & 29 & 3 & 0 & 3 & 16 & 2 & 1 & 0 \\
\hline Total & 27 & 27 & 43 & 4 & 9 & 8 & 29 & 29 & 18 & 10 \\
\hline
\end{tabular}

Elaboração do autor

Comparando as tabelas 3 e 4, percebemos que, nos vídeos das entidades patronais, a tendência do prevalecimento de características do paradigma dominante nas mensagens desaparece quando se trata de fatores de risco psicossociais e agravos mentais. No entanto, deve-se ressaltar que a amostra de vídeos de entidades patronais, fazendo referência a fatores de risco psicossociais ou agravos mentais, foi pequena no corpus, apenas 4 vídeos.

Tabela 4 - Frequências dos elementos do "paradigma dominante" e da "abordagem sistêmica" nas mensagens dos vídeos quando tratam de fatores de risco psicossociais e agravos mentais.

\begin{tabular}{|c|c|c|c|c|c|c|c|c|c|c|}
\hline & \multicolumn{10}{|c|}{ Patores de risco psicossociais e agravos mentais } \\
\hline Vídeos & \multicolumn{1}{|c|}{ Paradigma dominante } & Abordagem sistêmica \\
\hline & i & ii & iii & iv & v & vi & vii & a & b & c \\
\hline Estatais & 0 & 1 & 1 & 0 & 2 & 0 & 2 & 2 & 2 & 1 \\
\hline Sindicais & 0 & 0 & 0 & 0 & 1 & 0 & 0 & 15 & 2 & 6 \\
\hline Patronais & 1 & 0 & 0 & 0 & 0 & 0 & 1 & 1 & 0 & 0 \\
\hline Total & 1 & 1 & 1 & 0 & 3 & 0 & 3 & 18 & 4 & 7 \\
\hline
\end{tabular}

Comparando as tabelas 3 e 5, podemos observar que há proporcionalmente uma frequência maior de elementos da abordagem sistêmica em relação ao paradigma dominante quando doenças são abordadas, relativamente ao que encontramos quando não discriminamos o tipo de consequências e agravos que as mensagens abordam, e mesmo se desconsiderarmos os vídeos das entidades sindicais.

Tabela 5 - Frequências dos elementos do "paradigma dominante" e da "abordagem sistêmica" nas mensagens dos vídeos quando tratam de doenças. 
Dos fatores individuais aos sociais: paradigmas em Segurança e Saúde no Trabalho em campanhas preventivas audiovisuais no Brasil

\begin{tabular}{|c|c|c|c|c|c|c|c|c|c|c|}
\hline \multirow{3}{*}{ Vídeos } & \multicolumn{10}{|c|}{ Doenças } \\
\hline & \multicolumn{7}{|c|}{ Paradigma dominante } & \multicolumn{3}{|c|}{ Abordagem sistêmica } \\
\hline & $\mathbf{i}$ & ii & iii & iv & $\mathbf{v}$ & vi & vii & $\mathbf{a}$ & $\mathbf{b}$ & $\mathbf{c}$ \\
\hline Estatais & 1 & 1 & 1 & 0 & 0 & 0 & 1 & 3 & 2 & 1 \\
\hline Sindicais & 0 & 0 & 0 & 0 & 1 & 0 & 0 & 11 & 2 & 4 \\
\hline Patronais & 2 & 2 & 7 & 0 & 0 & 0 & 5 & 1 & 1 & 0 \\
\hline Total & 3 & 3 & 8 & 0 & 1 & 0 & 6 & 15 & 5 & 5 \\
\hline
\end{tabular}

Elaboração do autor

Podemos perceber, pela Tabela 6, que em vídeos que tratam de acidentes, que resultem ou não em morte ou intoxicação, prevalece a abordagem sistêmica nas mensagens dos vídeos dos sindicatos de trabalhadores. O que mostra como a abordagem sistêmica está mais vinculada a esse ator, com relativa independência se se trata de prevenção de acidentes ou de doenças de trabalho. Foram 21 vídeos de entidades estatais que abordavam acidentes, morte ou intoxicação, 2 de entidades sindicais e 20 de entidades patronais.

Comparando as frequências das tabelas 5 e 6 , podemos perceber que mesmo quando se trata de doenças, as mensagens dos vídeos das entidades patronais ainda têm uma leve tendência de privilegiar elementos do paradigma dominante nas suas mensagens. Quando trata de acidentes, essa tendência é muito nítida, com os elementos do paradigma dominante tendo muito maior frequência que aqueles da abordagem sistêmica. Já no caso dos vídeos produzidos pelas entidades estatais, há uma ligeira tendência de maior frequência dos elementos da abordagem sistêmica quando o vídeo aborda doenças.

Apesar dos aportes ou modelos sistêmicos como os de Reason (1990) e Rasmussen (1997) dominarem o campo científico da prevenção de acidentes de trabalho, e setores como a aviação comercial, cujos negócios dependem de altíssimos níveis de segurança, adotarem e desenvolverem a prevenção a partir de modelos sistêmicos, essa abordagem ainda não predomina na prevenção de acidentes de forma geral. Pelo menos levando em conta as mensagens do corpus de vídeos analisados. Uma vez que não conseguimos observar mudança de tendência nos vídeos de entidades estatais antes e após 2016, quando houve uma mudança abrupta de linha política governamental, o fato de os elementos do paradigma dominante estarem pelo menos tão presentes quanto os da abordagem sistêmica nos vídeos produzidos por esses atores, provavelmente possa ser explicado por esses elementos do paradigma dominante, centrados na individualização, terem caráter de senso comum, como aponta Filgueiras (2017). E se denominamos de paradigma dominante esse tipo-ideal,

Laborare. Ano III, Número 4, Jan-Jun/2020, pp. 15-31. ISSN 2595-847X. https://trabalhodigno.org/laborare DOI: https://doi.org/10.33637/2595-847x.2020-43 
naturalmente, esperávamos que ele prevalecesse nas campanhas preventivas no conjunto da sociedade.

Tabela 6 - Frequências dos elementos do "paradigma dominante" e da "abordagem sistêmica" nas mensagens dos vídeos quando tratam de acidentes, morte ou intoxicação.

\begin{tabular}{|c|c|c|c|c|c|c|c|c|c|c|}
\hline & \multicolumn{10}{|c|}{ Acidentes, morte e intoxicação } \\
\hline Vídeos & \multicolumn{1}{|c|}{ Paradigma dominante } & \multicolumn{3}{|c|}{ Abordagem sistêmica } \\
\hline & i & ii & iii & iv & v & vi & vii & a & b & c \\
\hline Estatais & 8 & 7 & 12 & 1 & 6 & 5 & 11 & 6 & 10 & 3 \\
\hline Sindicais & 0 & 0 & 0 & 0 & 0 & 0 & 0 & 4 & 1 & 2 \\
\hline Patronais & 18 & 17 & 28 & 3 & 0 & 3 & 14 & 1 & 1 & 0 \\
\hline Total & 26 & 24 & 40 & 4 & 6 & 8 & 25 & 11 & 12 & 5 \\
\hline
\end{tabular}

Elaboração do autor

A comparação dos valores das tabelas 3 e 7 não nos permite visualizar uma alteração significativa quanto ao tipo de paradigma ou modelo de prevenção nas mensagens dos vídeos que tratam o setor de serviços, em relação às frequências gerais. Nos dois vídeos produzidos por entidades patronais, do corpus, não foi possível reconhecer elementos do paradigma dominante nem da abordagem sistêmica de prevenção em SST.

Tabela 7 - Frequências dos elementos do "paradigma dominante" e da "abordagem sistêmica" nas mensagens dos vídeos quando tratam do setor de serviços.

\begin{tabular}{|c|c|c|c|c|c|c|c|c|c|c|}
\hline \multirow{3}{*}{ Vídeos } & \multicolumn{10}{|c|}{ Serviços } \\
\hline & \multicolumn{7}{|c|}{ Paradigma dominante } & \multicolumn{3}{|c|}{ Abordagem sistêmica } \\
\hline & $\mathbf{i}$ & ii & iii & iv & $\mathbf{v}$ & vi & vii & $\mathbf{a}$ & $\mathbf{b}$ & $\mathbf{c}$ \\
\hline Estatais & 1 & 1 & 2 & 0 & 1 & 1 & 1 & 2 & 2 & 0 \\
\hline Sindicais & 0 & 0 & 0 & 0 & 1 & 0 & 0 & 13 & 2 & 4 \\
\hline Patronais & 0 & 0 & 0 & 0 & 0 & 0 & 0 & 0 & 0 & 0 \\
\hline Total & 1 & 1 & 2 & 0 & 2 & 1 & 1 & 15 & 4 & 4 \\
\hline
\end{tabular}

Elaboração do autor

A diferença que encontramos, ou seja, de a abordagem sistêmica estar mais presente nas campanhas preventivas de sindicatos dos trabalhadores e o paradigma dominante mais presente nas das entidades patronais, possivelmente é explicável pelo conteúdo ideológico que cada modelo preventivo carrega, como vimos anteriormente. $\mathrm{O}$ 
Dos fatores individuais aos sociais: paradigmas em Segurança e Saúde no Trabalho em campanhas preventivas audiovisuais no Brasil

paradigma dominante, por exemplo, se adequaria melhor aos interesses patronais de manutenção de controle e poder discricionário sobre as condições de trabalho e o processo produtivo.

A estratégia de ocultação dos agravos, como apresentada por Filgueiras (2017), pode ser uma hipótese para explicar, pelo menos parcialmente, outras associações que encontramos (como entre fatores de risco psicossociais, doenças, sindicatos de trabalhadores e a abordagem sistêmica por um lado, e acidentes, paradigma dominante e entidades patronais, por outro). A hipótese seria de que as entidades empresariais tenderiam a fazer campanhas preventivas em SST quando a ocultação não é possível ou é difícil, e quando a estratégia de individualização também não é fácil. Doenças como LER/Dort e patologias mentais (as que causam mais afastamentos previdenciários) costumam ser mais facilmente negadas/ocultadas como estando relacionadas ao trabalho. No entanto, se essa ocultação é mais fácil nas doenças em geral (BROWN; LONG, 2018; ZOLLER, 2009), a individualização, isto é, a atribuição de culpa ou responsabilidade ao trabalhador pode ser mais difícil. Dessa perspectiva, surge, então, a hipótese de que as campanhas preventivas de entidades patronais tendem a abordar acidentes, ao menos em parte, pela ocultação, por não se mostrar eficaz nesses casos. Campanhas essas que tendem a usar o que definimos como o paradigma dominante em SST, o qual se adequa à estratégia de individualização. Por outro lado, as entidades sindicais dos trabalhadores, focando no terciário e nas doenças, fariam o esforço oposto: de publicizar e desocultar esses adoecimentos como relacionados ao trabalho.

\section{CONCLUSÕES}

Vimos que em vídeos sobre fatores de risco psicossociais e doenças, produzidos por quaisquer dos atores sociais, o paradigma dominante tem menos presença se comparado a vídeos envolvendo risco de acidentes e intoxicação. Apesar disso, a diferença de prevalência do paradigma dominante entre entidades, sindicatos, estatais e patronais, parece nos mostrar que as abordagens das empresas nas campanhas preventivas públicas pautam-se principalmente pela sua função ideológica, isto é, individualizando a segurança e saúde no trabalho e ocultando relações de poder.

Nos vídeos das entidades estatais, constatamos uma presença similar das duas abordagens que constituíram nossos tipos-ideais. Concordando com Filgueiras (2017), que a abordagem no ambiente e as condições de trabalho tendem a ser mais eficazes em termos preventivos, parece ser desejável que as entidades estatais se afastem mais do senso comum da individualização da prevenção, utilizando ainda

Laborare. Ano III, Número 4, Jan-Jun/2020, pp. 15-31. ISSN 2595-847X. https://trabalhodigno.org/laborare DOI: https://doi.org/10.33637/2595-847x.2020-43 
mais uma abordagem sistêmica em suas mensagens. Nesse sentido, uma limitação evidente desta pesquisa é não poder fornecer uma compreensão de como ocorre o processo de decisão e produção desses vídeos, isto é, o processo que faz uma abordagem acabar prevalecendo. Caminhar no sentido de uma ampliação de abordagens sistêmicas em SST, nas campanhas produzidas por órgãos governamentais, no entanto, pode encontrar atualmente o obstáculo do clima políticosocial autoritário, descrito por Waring (2019), no qual a negação da ciência que tem emergido com uma nova direita, que ganha poder em diversos países, pode vir a enfraquecer a influência do campo científico nas decisões e políticas de SST, com prejuízo, portanto, principalmente para as abordagens focadas em fatores ambientais e sociais.

Por fim, é preciso salientar que, para além dos limites intrínsecos à própria metodologia da pesquisa, o fato de termos nos concentrado apenas em materiais audiovisuais, publicizados em uma plataforma online, constitui uma limitação da pesquisa, de modo a apreender o mais fidedignamente possível as tendências de abordagens que prevalecem em campanhas preventivas de SST no Brasil.

\section{REFERÊNCIAS}

AARTS, B.; BAUER, M. A construção do corpus: um princípio para a coleta de dados qualitativos. In: BAUER, Martin; GASKELL, George (org.). Pesquisa Qualitativa com Texto, Imagem e Som: um manual prático. Petrópolis: Vozes, 2008. p. 39-63.

ALEXANDER, Jacqui. The Ideological Construction of Risk: an analysis of corporate health promotion programs in the 1980s. Soc. Sci. Med., v. 16, n. 15, p. 559-567, 1998. DOI: 10.1016/0277-9536(88)90389-9.

ALLENDER, S.; COLQHOUN, D.; KELLY, P. Governing the work population through workplace health: knowledge, self and power in workplace health programs. Critical Public Health, v. 16, n. 2, p.131-142, jun., 2006. Disponível em: https://doi.org/10.1080/09581590600828519.

ALMEIDA, I. M. Trajetória da análise de acidentes: o paradigma tradicional e os primórdios da ampliação da análise. Interface - Comunic., Saúde, Educ., v.10, n. 19, p.185-202, jan./jun., 2006. Disponível em: http://dx.doi.org/10.1590/S1414$\underline{32832006000100013}$.

BETONI, C. S. O Espírito dos Donos: empreendedorismo como projeto de adaptação da juventude. Florianópolis: Em Debate, 2016. 
Dos fatores individuais aos sociais: paradigmas em Segurança e Saúde no Trabalho em campanhas preventivas audiovisuais no Brasil

BROWN, V.; LONG, V. Conceptualizing work-related mental distress in the British coalfields (c.1900-1950). Palgrave Communications, 4:133, 2018. DOI: 10.1057/s41599-018-0187-4.

DAVIES, J. Back to balance: labour therapeutics and the depoliticisation of workplace distress. Palgrave Communications 2:16027, 2016. DOI: 10.1057/palcomms.

FALEIROS, V. P. O Trabalho da Politica: Saúde e Segurança dos Trabalhadores. São Paulo: Cortez, 1992.

FILGUEIRAS, V. A. Individualização, saúde e segurança do trabalho no Brasil. In: FILGUEIRAS, V. A. (org.). Saúde e Segurança do Trabalho no Brasil. Brasília: Gráfica Movimento, 2017.

GULIJK, C.V.; SWUSTE, P.; ZWAARD, W. Safety metaphors and theories, a review of the occupational safety literature of the US, UK and The Netherlands, till the first part of the 20th century. Safety Science, v. 48, p. 1000-1018, 2010. Disponível em: https://doi.org/10.1016/j.ssci.2010.01.020

HALL, A. The Ideological Construction of Risk in Mining: A Case Study. Critical Sociology, v. 22, n. 1, p. 93-116, 1996.

LIBERATO, L. V. M. Viradas do Avesso: percepção dos trabalhadores, constituição e existência de ferramentas de SST. Revista Latinoamericana de Estudios del Trabajo, v. 19, p. 39-64, 2014.

MENÉNDEZ-NAVARRO, A. A Arte de Prevenção em Segurança e Saúde no Trabalho. São Paulo: Fundacentro, 2019.

NAVARRO, V. Work, Ideology and Science: The case of Medicine. International Journal of Health Services, v.10, n. 4, 1980. Disponível em: https://doi.org/10.2190/6EAJ-HEXP-UBQG-GK4A

NEGRO, A. L. Linhas de Montagem: o industrialismo nacional-desenvolvimentista e a sindicalização dos trabalhadores (1945-1978). São Paulo: Boitempo, 2004.

NELKIN, D. (Ed.). The Language of Risk: Conflicting Perspectives on Occupational Health. Beverly Hills: Sage, 1985.

NICHOLS, T. Death and Injury at Work: A Sociological Approach. In: DAYKIN, N.; DOYAL, L. (Ed.). Health and Work: Critical Perspectives. New York: St. Martin, 1999. 
PFEFFER, J. Dying for a Paycheck: how modern management harms employee health and company performance - and what we can do about it. New York: Harper Business, 2018.

RASMUSSEN, J. (1997). Risk management in a dynamic society: a modeling problem. Safety Science, v. 27, n. 2, p.183-213, 1997. Disponível em: https://doi.org/ 10.1016/S0925-7535(97)00052-0

REASON, J. Human Error. Cambridge: Cambridge University Press, 1990.

ROSE, D. (2008). Análise de imagens em movimento. In: BAUER, M.; GASKELL, G. (org.). Pesquisa Qualitativa com Texto, Imagem e Som: um manual prático. Petrópolis: Vozes, 2008. p. 343-364.

WALTERS, V. (1985). The Politics of Occupational Health and Safety: interviews with workers' health and safety representatives and company doctors. Canadian Reviews of Sociology and Anthropology, v. 22, n. 1, p. 56-79, 1985. Disponível em: https://doi.org/10.1111/j.1755-618X.1985.tb00717.x

WARING, A. The five pillars of occupational safety \& health in a context of authoritarian socio-political climates. Safety Science, v. 117, p. 152-163, 2019. Disponível em: https://doi.org/10.1016/j.ssci.2019.04.008

WEBER, M. (1999). A objetividade do conhecimento nas ciências sociais. In: COHN, G. (org.). Max Weber. São Paulo: Ática. (Coleção Weber: sociologia).

ZOLLER, H. M. (2009). The Social Construction of Occupational Health and Safety. New Solutions, v. 19, n. 3, p. 289-314. DOI: 10.2190/NS.19.3.b.

Recebido: 30/12/2019

Revisado: $14 / 04 / 2020$

Aprovado: 08/06/2020 